\title{
BMJ Open A UK survey of rehabilitation following critical illness: implementation of NICE Clinical Guidance 83 (CG83) following hospital discharge
}

\author{
Bronwen Connolly, ${ }^{1,2,3}$ A Douiri, ${ }^{4}$ J Steier, ${ }^{3} \mathrm{~J}$ Moxham, ${ }^{1}$ L Denehy, ${ }^{5} \mathrm{~N}$ Hart ${ }^{1,2,3}$
}

To cite: Connolly B, Douiri A, Steier J, et al. A UK survey of rehabilitation following critical illness: implementation of NICE Clinical Guidance 83 (CG83) following hospital discharge. BMJ Open 2014:4: e004963. doi:10.1136/ bmjopen-2014-004963

- Prepublication history and additional material is available. To view please visit the journal (http://dx.doi.org/ 10.1136/bmjopen-2014004963).

Received 29 January 2014 Revised 1 April 2014 Accepted 18 April 2014

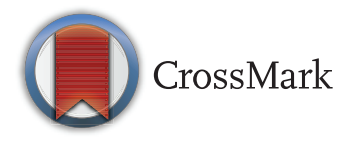

For numbered affiliations see end of article.

Correspondence to Bronwen Connolly; bronwen.connolly@nhs.net

\section{ABSTRACT}

Objective: To determine the implementation of National Institute for Health and Care Excellence guidance (NICE CG83) for posthospital discharge critical illness follow-up and rehabilitation programmes.

Design: Closed-question postal survey.

Setting: Adult intensive care units (ICUs) across the UK, identified from national databases of organisations. Specialist-only and private ICUs were not included.

Participants: Senior respiratory critical care physiotherapy clinicians.

Results: A representative sample of 182 surveys was returned from the 240 distributed $(75.8 \%(95 \% \mathrm{Cl}$ 70.4 to 81.2$))$. Only 48 organisations $(27.3 \%(95 \% \mathrm{Cl}$ 20.7 to 33.9)) offered a follow-up service $2-3$ months following hospital discharge, the majority $(\mathrm{n}=39$, $84.8 \%$ ) in clinic format. 12 organisations reported posthospital discharge rehabilitation programmes (6.8\% (95\% Cl 3.1 to 10.5$))$, albeit only 10 of these operated on a regular basis. Lack of funding was reported as the most frequent $(n=149 / 164,90 \%)$ and main barrier ( $n=99 / 156,63.5 \%$ ) to providing services. Insufficient resources ( $n=71 / 164,43.3 \%$ ) and lack of priority by the clinical management team $(n=66 / 164$, $40.2 \%$ ) were also highly cited barriers to service delivery.

Conclusions: NICE CG83 has been successful in profiling the importance of rehabilitation for survivors of critical illness. However, 4 years following publication of CG83 there has been limited development of this clinical service across the UK. Strategies to support delivery of such quality improvement programmes are urgently required to enhance patient care.

\section{INTRODUCTION}

Intensive care unit (ICU) admission with critical illness can have catastrophic and often long-term consequences for survivors. Physical and psychological impairments including reduced exercise capacity and health-related quality of life can persist for many years following hospital discharge. ${ }^{1-4}$

\section{Strengths and limitations of this study}

- This is the largest and most comprehensive survey conducted across the UK of posthospital discharge follow-up and rehabilitation for survivors of critical illness.

- Data from this survey indicate a low-reported prevalence of available services, with barriers to service implementation reported by clinicians examined in detail.

- This survey was profession specific, directed only to physiotherapy clinicians rather than multiple members of the interdisciplinary team.

- Specialist-only and private organisations were excluded, which may have provided additional, potentially beneficial data.

These features are now referred to as the 'postintensive care syndrome'. 5 In recent years the importance of survivorship, or quality of survival, has been increasingly recognised, ${ }^{6}$ and the role of rehabilitation interventions to facilitate the recovery pathway of patients has become a major focus for the clinician. ${ }^{7}$

In the UK, the National Institute of Health and Care Excellence (NICE) in 2009 published clinical guideline 83 (CG83) focused on 'Rehabilitation After Critical Illness' (available at http://publications.nice.org.uk/ rehabilitation-after-critical-illness-cg83). This profiled the importance of this area of clinical practice aiming to improve the standards of care and previously unmet clinical needs of this patient group. NICE CG83 advocated a continuum of multidisciplinary rehabilitation along the recovery pathway from within the ICU to the ward and following hospital discharge, although these recommendations were largely based on expert consensus due to the lack of published evidence. Specifically, at the point of hospital discharge, it is recommended that patients are referred 
to appropriate rehabilitation services if ongoing needs are identified. At 2-3 months following hospital discharge, a review and functional reassessment of the patient should be undertaken to determine the extent of recovery and additional rehabilitation input should be provided in the event of a slower-than-anticipated recovery or identification of new physical and/or psychological morbidity. ${ }^{8}$

Despite the intentions, widespread clinical implementation of these guidelines has been challenged by the limited evidence underpinning the recommendations, as well as sparse detail provided to characterise the optimum type, intensity, frequency and duration of exercise therapy and rehabilitation interventions. ${ }^{9}$ Furthermore, critical care survivors experience inadequate and disjointed multidisciplinary care following hospital discharge with inconsistent service provision, which can be strongly influenced by local resources and geographical location. ${ }^{10}$

Failure to implement national guidelines or respond to published evidence is not uncommon. Disparity between the prevalence of conditions such as chronic cardiorespiratory disease, diabetes mellitus and sleep-related disorders, and availability of recommended services for their management is evident across the UK. ${ }^{11-13}$ Previous surveys relating to provision of critical care rehabilitation have focused on ICU follow-up ${ }^{14}$ or physiotherapy practice within the ICU. ${ }^{15-17}$ Two recent surveys reported on NICE CG83, but these were limited in content and detail. ${ }^{18} 19$ The aim of the current study was to comprehensively determine, across the UK, implementation of NICE CG83 during the posthospital discharge period with detailed characterisation of available follow-up and rehabilitation services, and including establishing barriers to service provision.

\section{METHODS}

Details for all adult ICUs across the UK (England, Scotland, Wales and Northern Ireland) were obtained via two central registries, the Intensive Care National Audit and Research Centre (ICNARC) and the Scottish Intensive Care Society Audit Group (SICSAG). A total of 240 organisations were identified (85 university teaching (UT) hospitals and 155 district general (DG) hospitals). Specialist-only and private ICUs were excluded from the survey.

The authors designed a predominantly closedquestion survey (see online supplementary file 1) to evaluate clinical practice regarding follow-up and rehabilitation services for survivors of critical illness posthospital discharge. Demographic details were requested regarding number, type and bed capacity of critical care areas at each organisation. In addition, detail of service provision including follow-up, content, delivery and evaluation of rehabilitation programmes was requested, and barriers to offering services were sought if none were currently in operation. The majority of questions allowed respondents to select from multiple options with space available for free-text comments throughout. These options were not ranked, nor were respondents asked to mark their response in terms of perceived importance or grading, with the exception of asking respondents to detail the main limiting barrier to service availability. The survey was piloted by three senior physiotherapy clinicians and clinical-academics (ICU clinical experience ranging from 7 to 14 years) at two tertiary referral UT hospitals in London, UK. Constructive critique of survey design, content, structure, user acceptability and time for completion was requested, following which further refinement was undertaken.

In March 2013, the survey and a covering letter of invitation to participate were distributed by post to the senior physiotherapist for critical care at each of the organisations with an included ICU. Stamped, selfaddressed envelopes (SAEs) were enclosed for return of completed surveys. Surveys were coded to identify responses. Throughout the period of survey distribution a variety of strategies were employed to assist with survey promotion and enhance rates of completion and return. Six weeks following initial survey distribution, a reminder letter was sent by post to non-responders with a second copy of the survey and further SAEs. A further 6 weeks later, telephone calls were made to remaining non-responders. Direct contact was attempted with the senior critical care physiotherapists to determine their willingness to participate, and were offered the choice of telephone or email completion of the survey. Respondents were also contacted via email or telephone if there were missing data.

\section{Data handling}

In line with guidance produced by the UK National Research Ethics Service (available at http://www.nres. nhs.uk/) the project was deemed an evaluation of service provision, and therefore ethical approval was not required. Completion and return of the survey was considered indicative of willingness to participate in the survey and implied consent. All data were stored in standard spreadsheets, transcribed from hard copies of returned surveys. Owing to the nature of the study and data collected, descriptive statistics were used to analyse quantitative responses including number, percentage and $95 \%$ CIs where appropriate, and additional qualitative review of free-text comments made. A response rate of $65 \%$ rate was considered a priori to provide a representative sample.

\section{RESULTS}

\section{Responding institutions}

One hundred and eighty-two of the 240 distributed surveys were returned, indicating an overall response rate of $75.8 \%$ (95\% CI $70.4 \%$ to $81.2 \%$; figure 1 ). Specifically, nearly three quarters of all surveys distributed to UT and 


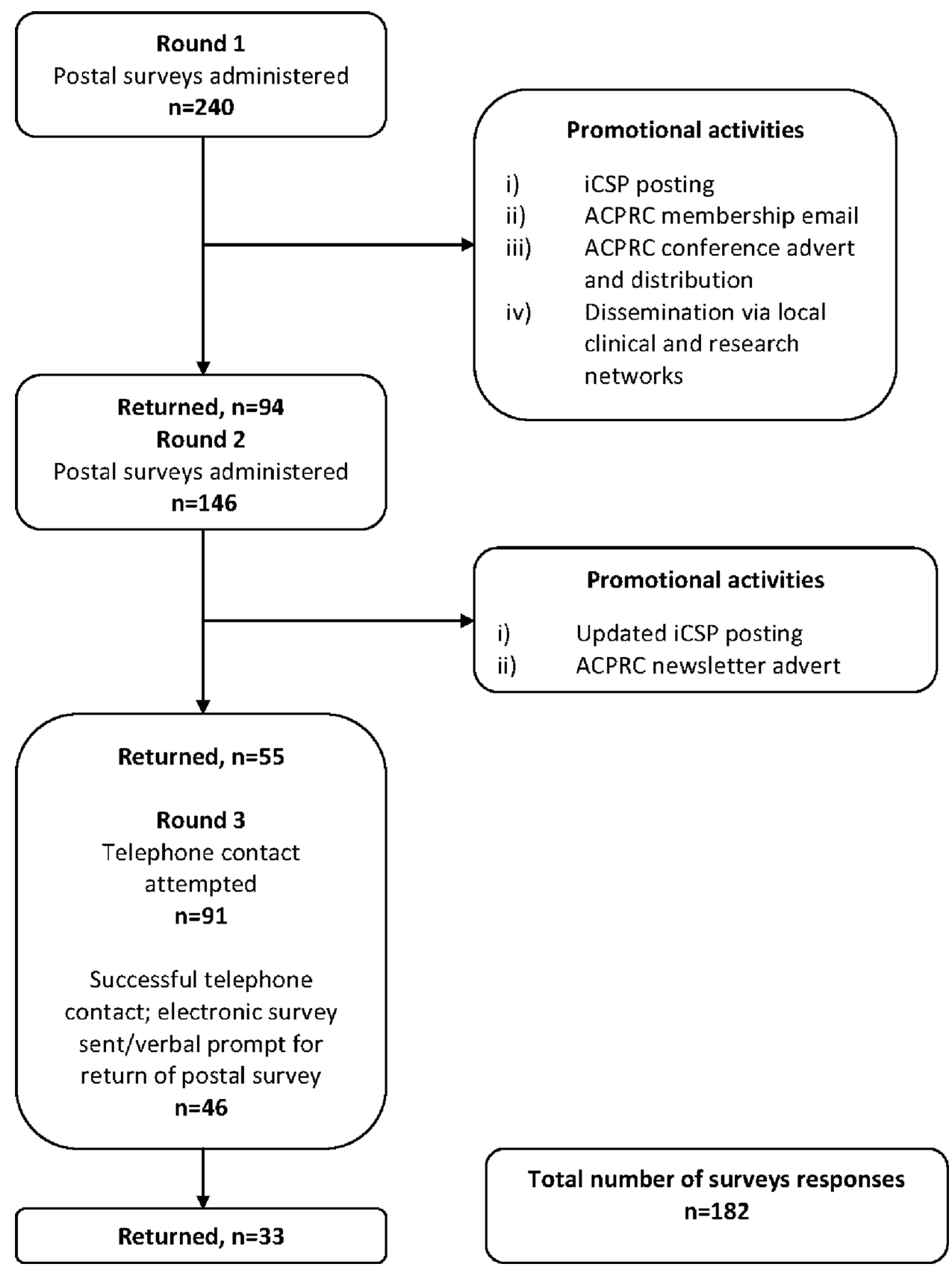

Figure 1 Flowchart of survey distribution stages, response rates and promotional activities. ACPRC, Association of Chartered Physiotherapists in Respiratory Care; iCSP, interactive Chartered Society of Physiotherapy.

DG hospitals were returned $(66 / 85,75 \%$ and $115 / 155$, $74.2 \%$, respectively) indicating that the groups of respondents were a representative sample of the original cohort of organisations. One survey was returned blank with the respondent indicating that they lacked sufficient time for completion. Demographic data for the hospitals surveyed are reported in table 1 . The majority were DG hospitals with ICUs and high dependency units managing mixed general medical and surgical patient casemixes. A large number of responses reported 'combination' units accepting level 3 and 2 patients (table 2).

Five respondents reported that available rehabilitation programmes at their organisations were the direct result of active research studies (see online supplementary figure E1, file 2). These responses were excluded as the aim of the survey was to characterise current clinical practice rather than research activity. These five respondents completed the survey section detailing barriers to offering a clinical service had the research study not been implemented.

\section{Posthospital discharge follow-up clinical services}

Forty-eight organisations $(27.3 \%, 95 \%$ CI $(20.7 \%$ to $33.9 \%)$ ) reported availability of follow-up for postcritical illness patients at 2-3 months following hospital discharge (see online supplementary figure E1, file 2 and 3 ). 
Table 1 Demographics of respondent organisations

\begin{tabular}{|c|c|}
\hline Characteristic & $\mathbf{N}(\%)$ \\
\hline \multicolumn{2}{|c|}{ Response rate according to the UK country } \\
\hline England & $145(75.1$ \\
\hline Scotland & $20(87.0$ \\
\hline Wales & $12(80.0$ \\
\hline Northern Ireland & $5(55.6$ \\
\hline \multicolumn{2}{|l|}{ Type of hospital } \\
\hline University teaching & $66(36.5$ \\
\hline District general & $115(63.5$ \\
\hline \multicolumn{2}{|l|}{ Total number of critical care units ${ }^{*}$} \\
\hline Level 3 (ICU) & 112 \\
\hline Level 2 (HDU) & 170 \\
\hline Combination levels 3 and 2 units & 98 \\
\hline \multicolumn{2}{|l|}{ Total number of critical care beds* } \\
\hline Level 3 (ICU) & 1007 \\
\hline Level 2 (HDU) & 1090 \\
\hline Combination levels 3 and 2 units & 1354 \\
\hline \multicolumn{2}{|c|}{$\begin{array}{l}\text { Frequency of reported types of patients admitted to critical } \\
\text { care unit* } \dagger\end{array}$} \\
\hline General & 230 \\
\hline Surgical & 52 \\
\hline Medical & 38 \\
\hline Cardiac/cardiology/cardiothoracic & 35 \\
\hline Neurological & 22 \\
\hline Respiratory & 17 \\
\hline Trauma & 14 \\
\hline Renal & 5 \\
\hline Burns & 4 \\
\hline Liver & 4 \\
\hline ENT & 3 \\
\hline Otherł & 10 \\
\hline
\end{tabular}

$\mathrm{n}=181$ responses (except for response rate according to country, $\mathrm{n}=192$ responses). Critical care units and bed numbers refer to the total number within respondent organisations overall, for example, one organisation may have multiple critical care areas. ${ }^{*} \mathrm{n}=2$ non-responses.

†Data presented indicate frequency of reported occurrence of type. Multiple responses could be given.

fOther, for example, haematology, infectious disease, maxillofacial, vascular.

ENT, ear, nose, throat; HDU, high dependency unit; ICU, intensive care unit.

Thirty-two $(66.7 \%)$ of these were from DG hospitals and $16(33.3 \%)$ from UT hospitals. Forty-five organisations offering follow-up were located in England, two in Scotland, one in Northern Ireland and none in Wales. Two respondents did not provide details of follow-up provision. Of the remaining responses $(n=46)$, ICU follow-up clinics were the most frequently reported form of follow-up $(\mathrm{n}=39,84.8 \%)$ (table 3). Eleven respondents reported more than one form of follow-up was in place.

Forty-three $(89.6 \%)$ respondents reported that physiotherapists were part of the multidisciplinary team (MDT) involved in follow-up of postcritical illness patients. However, just under one-third of these, $n=13$ $(30.2 \%)$, reported that this was on an ad hoc referral basis only. Other MDT members involved in follow-up are detailed in table 3. In five cases access to critical care
Table 2 Classifications of level of clinical care provided to patients

\section{Level Classification}

$0 \quad$ Patients whose needs can be met through normal ward care in an acute hospital

1 Patients at risk of their condition deteriorating, or those recently located from higher levels of care, whose needs can be met on an acute ward with additional advice and support from the critical care team

2 Patients requiring more detailed observation or intervention including support for a single failing organ system or postoperative care and those 'stepping down' from higher levels of care

3 Patients requiring advanced respiratory support alone or basic respiratory support together with support of at least two organ systems. This level includes all complex patients requiring support for multiorgan failure

From Comprehensive Critical Care, DH, $2000{ }^{20}$

doctors, occupational therapists, psychologists or dieticians was also reported to be on a referral basis only. Critical care nurses were the most consistently featured MDT members and occupational therapists and dieticians were rarely involved in follow-up. The scale of MDT involvement ranged from one member $(10.4 \%)$ to five members $(2 \%)$, with three being the most common $(43.8 \%)$. No other healthcare professionals, other than those listed, were documented to be part of the MDT.

Nearly half of those with follow-up services included a functional reassessment for comparison with assessment conducted at the time of hospital discharge $(n=20$, $42.6 \%)$. Table 3 details other aspects of follow-up assessments; health-related quality of life $(n=40,83.3 \%)$ and psychological status $(n=39,81.3 \%)$ were the most frequently reported items. Exercise capacity and nursing-related issues were included in approximately half of the cases.

\section{Availability of posthospital discharge rehabilitation programmes}

Twelve organisations reported a rehabilitation programme was available following hospital discharge for postcritical illness patients $(6.8 \%, 95 \%$ CI $(3.1 \%$ to $10.5 \%$ ); see online supplementary figure E1, file 2). Two reported that their programme was only available on an ad hoc basis. Of the remaining 10 programmes implemented on a regular basis, $4(40 \%)$ were conducted at UT hospitals and $6(60 \%)$ at DG hospitals), and all based at organisations in England. All had also reported offering a follow-up service, with eight of these in the form of an ICU follow-up clinic.

Senior ICU physiotherapists led all available rehabilitation programmes, with the exception of one led by a rehabilitation physiotherapist. The majority $(n=9)$ were hospital-based outpatient programmes, specific for 
Table 3 Follow-up services for critical care survivors posthospital discharge

\begin{tabular}{lc}
\hline & N (\%) \\
\hline Form of follow-up & \\
ICU follow-up clinic & $39(84.8)$ \\
Rehabilitation class & $10(21.7)$ \\
Other & $6(13.0)$ \\
Did not specify & $2(4.3)$ \\
Postal survey & $1(2.2)$ \\
Telephone call & $1(2.2)$ \\
Medical outpatient appointment & $0(0)$ \\
Multidisciplinary team member & \\
Physiotherapist & $43(89.6)$ \\
Critical care nurse & $42(87.5)$ \\
Critical care doctor & $31(64.6)$ \\
Psychologist & $10(20.8)$ \\
Dietician & $2(4.2)$ \\
Occupational therapist & $2(4.2)$ \\
Content of follow-up & \\
HRQL & $40(83.3)$ \\
Psychological status & $39(81.3)$ \\
Medical status & $34(70.8)$ \\
Nursing-related issues & $29(60.4)$ \\
Exercise capacity & $28(58.3)$ \\
Diet/nutrition & $24(50.0)$ \\
Other & $9(18.8)$ \\
\hline For & \\
\hline
\end{tabular}

For follow-up, $n=$ frequency of reported occurrence out of 46 responses. Multiple forms of follow-up could be indicated. Other included informal coffee morning, patient support group, physiotherapy outreach, ad hoc appointments with ICU nursing staff. For multidisciplinary team members, $n=$ frequency of reported occurrence out of 48 responses. Multiple team members could be listed. For follow-up content, $n=$ frequency of reported occurrence out of 48 responses. Multiple content could be listed. Other included 'problem-based' or 'patient-dependent' discussion. $\mathrm{HRQL}$, health-related quality of life; ICU, intensive care unit.

postcritical illness patients. Exercise was a component of all programmes including cardiovascular, muscle strength, balance and functional activities. Exercise prescription was usually based on clinician judgement, and on occasion using results of physical assessment of walking capacity or function. Clinical and physiological parameters were used to monitor exercise intensity during sessions. Less than half of all programmes $(n=4)$ included education sessions. Measures used to evaluate effectiveness of these rehabilitation programmes varied greatly with exercise capacity and health-related quality of life most commonly reported.

Further detail on the leadership, format and structure, content and monitoring and evaluation of available posthospital discharge rehabilitation programmes can be found in online supplementary file 2 .

\section{Barriers to delivery of posthospital discharge rehabilitation programmes}

Respondents were requested to report the barriers to delivery of posthospital discharge rehabilitation programmes from a non-hierarchical list including clinical, pragmatic, managerial and administrative options. From the reasons selected, respondents were also requested to confirm the main reason. From a potential 171 responses, there were 7 non-responses to both parts of this question $(n=164)$, and a further 8 non-responses to specifying the main barrier $(n=156)$. Ninety-one per cent $(n=149)$ of respondents reported lack of funding as one barrier to offering a posthospital discharge rehabilitation programme and $75 \%$ reported lack of staff (table 4 ). Only $2.4 \%$ of respondents reported lack of evidence and less than $1 \%$ of respondents reported time constraints as barriers to implementing a posthospital discharge rehabilitation programme. Six per cent $(10 /$ 164 ) of respondents reported only one barrier, $20 \%$ $(33 / 164)$ reported two barriers and $73 \%(120 / 164)$ reported greater than two barriers.

\section{Alternative rehabilitation programmes}

In total, $57.3 \%(98 / 171)$ of respondents reported that in the absence of a specific posthospital discharge rehabilitation programme for survivors of critical illness

Table 4 Barriers to posthospital discharge rehabilitation programmes for survivors of critical illness

\begin{tabular}{llc}
\hline Barrier & $\begin{array}{l}\text { Frequency reported } \\
\text { overall, } \mathbf{n}(\%)\end{array}$ & $\begin{array}{l}\text { Frequency reported } \\
\text { as main barrier, } \mathbf{n}(\%)\end{array}$ \\
\hline Lack of funding & $149(90.9)$ & $99(63.5)$ \\
Lack of sufficient staff & $128(78.0)$ & $17(10.9)$ \\
Resources prioritised to other patient groups/clinical areas & $71(43.3)$ & $4(2.7)$ \\
Not considered required service at managerial level & $66(40.2)$ & $22(14.1)$ \\
Lack of available space & $50(30.5)$ & $2(1.3)$ \\
Insufficient patient numbers to justify & $35(21.3)$ & $11(7.1)$ \\
Extracontractual (out-of-area) patient caseload & $15(9.1)$ & $0(0.0)$ \\
Lack of trained staff & $13(7.9)$ & $0(0.0)$ \\
No evidence & $4(2.4)$ & $0(0.0)$ \\
Not sure what to include in a programme & $2(1.2)$ & $0(0.0)$ \\
Other (time constraints) & $1(0.6)$ & $1(0.6)$
\end{tabular}

For frequency of reported barriers overall, $n=164$ responses. For frequency of reporting as main barrier, $n=156$ responses. ( $n=182$ responses, excluding one blank response, 10 non-applicable responses relating to rehabilitation programmes in regular operation, seven non-responses to both parts of this question, and a further 8 non-responses to specifying the main barrier). 
at their organisation, patients were referred to alternative rehabilitation streams, including pulmonary rehabilitation (PR; 62/98, 63.3\%) and cardiac rehabilitation (38/98, 38.8\%; eg, those patients postcardiac surgery and postmyocardial infarction) and various communitybased services $(59 / 98 ; 60.2 \%)$. Free-text comments from respondents regarding barriers to offering rehabilitation programmes and the use of alternative rehabilitation streams for ICU survivors following hospital discharge can be found in the online supplementary data (E3).

\section{DISCUSSION}

These data from the first comprehensive UK survey highlight the limited implementation of NICE CG83 and poor delivery across the UK of posthospital rehabilitation services for survivors of critical illness. Indeed, of the 182 surveys returned, less than one-third of all institutions surveyed provided any form of follow-up for these patients. Of major clinical concern is that only $5 \%$ of respondents reported the provision of a regular rehabilitation programme for critical illness survivors, a major focus of CG83. Lack of funding was the most frequently reported and main barrier to service availability. Furthermore, lack of managerial support for this type of service and prioritisation of resource allocation to other clinical areas were reported as barriers by over $40 \%$ of the respondents. These data indicate that inadequate clinical infrastructure exists for hospitals and community teams to successfully adhere to NICE CG83. The limited impact of NICE guidance on clinical practice is not unique to critical care rehabilitation and is, rather disappointingly, a theme observed in other areas of healthcare that have been subject to the development of NICE guidelines.

\section{Implementation of NICE CG83 across the UK}

The lack of implementation of NICE CG83 evident from these data could have reflected poor motivation on the part of clinicians to actively engage in the delivery of recommendations. However, the key barriers to service delivery were reported as lack of funding, limited resources and infrastructure with reduced priority at managerial level. In the modern National Health Service (NHS), such obstacles to the application of NICE CG83 are at either a clinical commissioning or clinical operational level, or both, rather than at the level of the clinicians. Interestingly, the paucity of data to support the effectiveness of post-ICU rehabilitation was not perceived as a barrier by the vast majority of clinicians, and highlights the complexities in the management and clinical delivery of a critical care rehabilitation service. A conflict between clinicians, managers and commissioners has developed as the lack of high-level clinical evidence supporting NICE CG83 provides a major challenge to the funding of a critical care survivor rehabilitation service by managers and commissioners. Of note, the survey identified five respondents who reported availability of posthospital discharge rehabilitation services as part of existing research studies, ${ }^{21-23}$ examining the effect of various exercisebased interventions delivered in outpatient settings to postcritical illness patients following hospital discharge. At present, only abstract data are available from one of these studies, that demonstrate a significant improvement in exercise capacity and balance as a result of the intervention. ${ }^{24}$ Further data from this, and other similar studies, will assist in establishing the evidence base for postcritical illness rehabilitation.

\section{Alternatives to posthospital discharge rehabilitation programmes}

Rehabilitation for survivors of critical illness is a complex intervention $^{25}$ that requires further translational work and clinical trials to provide the evidence. ${ }^{26-28}$ Until these data are available, the unmet clinical need will remain evident and unaddressed. Referral to established rehabilitation programmes, such as cardiac and PR, offers one potential resolution with over $50 \%$ of respondents reporting the use of other rehabilitation programmes for the critical care survivors, and this may further be influenced by the designated specialty of the ward destination of patients following ICU discharge. Indeed the up-to-date guidelines for $\mathrm{PR}^{29}$ advocate individualised patient management and these interventions could be easily adapted for patients recovering from critical illness, although additional referrals place an increased burden on these services. However, while valuable resources, these programmes are disease specific and may not fully address the range of impairments demonstrated by survivors of critical illness as part of 'postintensive care syndrome'.

\section{The clinical usefulness of post-ICU clinics}

Post-ICU clinics provided the majority of available follow-up services in the current survey. Profiled in the late 1990s and early 2000s following updating of the NHS agenda for critical care, ${ }^{20}{ }^{30}$ these clinics have been reported by patients to play a valuable contribution to their physical, emotional and psychological recovery. ${ }^{31}$ However, trial data have failed to demonstrate clinical effectiveness or cost benefit. ${ }^{32}$ An alternative approach to the conduct and purpose of post-ICU clinics would be to robustly monitor over time the trajectory of recovery of ICU survivors with onward referral to specific specialty care where identified as required. Wide variability in responses regarding posthospital discharge rehabilitation programmes for ICU survivors severely limits any consensus on the optimum approach for these services. The marked heterogeneity of the patient population makes it increasingly likely that a bespoke, individualised approach, akin to the approach of personalised medicine may be more appropriate.

\section{Barriers to implementation of national guidelines}

The implementation of, and adherence to, a clinical guideline can be inconsistent. ${ }^{33} 34$ The limited detail in 
terms of the rehabilitation programme in the guideline per se as well as local conditions such as staff infrastructure, organisation and resource were the main source of restriction in the implementation of NICE CG83 in the current survey. ${ }^{35}$ This is the first survey to investigate reasons behind failure to implement such a national guideline and offer significant insight into the requirements necessary for successful clinical application of recommendations designed to enhance patient care. While the goals of NICE CG83 were important and raised the profile of this area of clinical practice the influence will be short lived without further investment in support systems at operational and staffing levels. Disappointingly, this scenario appears to be mirrored in other common clinical conditions. Although evidence supports the use of early PR following acute exacerbation of chronic obstructive pulmonary disease (AECOPD) to enhance exercise capacity, health status and reduce hospital re-admissions, ${ }^{29}{ }^{36-38}$ recent data suggest that only one-third of eligible patients are referred to early PR programmes and less than $10 \%$ of all hospital discharges for AECOPD complete early posthospitalisation PR. ${ }^{12}$ This implementation failure is also observed following the NICE guidance on the management of obstructive sleep apnoea ${ }^{39}$ with a recent national mapping exercise highlighting a significant mismatch between predictive healthcare requirements, based on prevalence of known associated risk factors, and delivery of related services. ${ }^{13}$ Furthermore, the 2012 NHS Atlas of Variation in Healthcare for People with Diabetes ${ }^{11}$ revealed substantial numbers of patients were not in receipt of the basic clinical standards of care. The barriers to the implementation of these guidelines are specific to each clinical area, but there are generic barriers, such as lack of adequate funding and resource, that need to be considered carefully. However, it must be highlighted that robust clinical trial and other data are required to support a guideline if it is to be commissioned within the NHS and delivering a guideline prematurely will lead to implementation failure, despite major enthusiasm by clinicians.

\section{Critique of the method}

A major strength of this survey is the employment of a variety of strategies to optimise completion, resulting in a $76 \%$ response rate. Nonetheless, survey non-response is a challenge to the robustness of the current findings, introducing bias through the potential for nonresponders to differ significantly from responders. ${ }^{40} 41$ Despite this, one must consider this as a most satisfactory return indicating external validity. ${ }^{41}{ }^{42}$ Furthermore, the sample of respondents was representative of the original cohort. High response rate may represent the clinical concern of the respondents in terms of poor implementation of NICE CG83, in particular, as the core standards for care of the critically ill patient have been recently published highlighting rehabilitation as an important core clinical care standard. ${ }^{43}$
Postal questionnaires can be preferable for conducting surveys of large populations over a wide geographical range, offering a cost-efficient as well as time-efficient format with often improved response rates in comparison to alternative routes such as telephone interview or email. ${ }^{44}$ Furthermore, an email or internet-based platform would have been restricted in the current study due to lack of available electronic contact details for named critical care physiotherapy clinicians, and where postal distribution offered a more standardised approach for monitoring and identifying respondents. Nonetheless, we acknowledge that in the current technology climate, many respondents may have preferred this option for survey participation. We utilised email and telephone contact at later stages of survey distribution as more feasible and less cost prohibitive means to target previous non-responders with good effect. Despite encountering some difficulty with locating designated senior clinicians ${ }^{45}$ this resulted in a relatively high conversion rate of $36 \%$ of non-responders. However, we recognise that it was not possible to control who was responsible for actual completion of the postal surveys returned, and that this may have been by more junior staff depending on local staffing arrangements, perceived importance and time constraints of senior clinicians. However, we also specified in the accompanying cover letter that respondents be in a position to comment on the content of the survey, and therefore this may have been appropriate for different personnel.

The current survey took advantage of a range of design and formatting strategies to enhance completion, additionally including a personalised cover letter and stamped addressed envelopes. ${ }^{41} 42{ }^{46}$ Survey review was undertaken during piloting with three senior physiotherapy clinical academics, and we aimed to minimise additional burden to potential respondents by not utilising a larger sample at this stage. Furthermore, we adopted an approach to survey distribution in keeping with that previously suggested to minimise non-response. ${ }^{47}$ However, the current survey lacked sufficient demographic or other data regarding non-responders to attempt comparison between the two groups, ${ }^{40} 41$ although $95 \%$ CIs are narrow supporting the respondents as representative sample of the whole respondent population.

We identified ICUs for inclusion based on data provided by two national registries (ICNARC and SICSAG). While specialist-only and private institutions were excluded, assuming that rehabilitation services offered to these patient cohorts may be influenced by disease-specific or institutional status-related factors, we acknowledge that future survey data acquired from these organisations may add further benefit to characterising service provision. We adopted a more rigorous approach to data acquisition than previous similar surveys that were country-specific $^{18}$ or excluded key regions, ${ }^{19}$ although these authors examined NICE CG83 implementation across the patient pathway and results observed at the posthospital discharge stage mirrored those of the current study. 
The current study focused on posthospital discharge management as it is at this stage that patients may be more likely to experience insufficient input for reasons such as lack of available services, repatriation to other geographical regions or follow-up under non-ICU teams. ${ }^{48}$ In contrast to previous surveys, we examined barriers to service availability in detail to gain further insight regarding this. Furthermore, rehabilitation for ICU survivors following hospital discharge has been the focus of recent research interest with randomised controlled trial data now available. ${ }^{49}$ The current survey could be critiqued for being discipline specific. However, it was considered that senior critical care physiotherapy clinicians would be well informed as key members of the multidisciplinary team involved in management of ICU survivors, to comment on follow-up and rehabilitation service provision at their institutions.

\section{CONCLUSION}

These data from this first comprehensive UK survey of posthospital discharge rehabilitation programmes for critical illness survivors have demonstrated a lowreported prevalence and, more importantly, this survey has showed a failure to implement NICE CG83. Lack of clinical prioritisation and funding was reported by the clinicians as the major cause for the failure to implement the guideline, but the paucity of evidence that supported the guideline must be regarded as a major contributor to the limited engagement between clinicians, managers and commissioners to deliver NICE CG83. Without clinical and cost-effectiveness evidence for such a programme, it would be a significant challenge to commission such a service in an NHS that is driven to commission clinical and specialist services with an established evidence base. The focus of the clinicians must be to ensure that clinical guidelines have a robust and strong evidence base to maximise their implementation and this will result in an enhancement in patient care that will be clinical and cost effective.

\section{Author affiliations}

${ }^{1}$ Department of Asthma, Allergy and Respiratory Science, Division of Asthma, Allergy and Lung Biology, King's College London, London, UK

'Guy's \& St Thomas' NHS Foundation Trust and King's College London, National Institute of Health Research Biomedical Research Centre, London, UK ${ }^{3}$ Lane Fox Clinical Respiratory Physiology Research Unit, St Thomas' Hospital, Guy's \& St Thomas' NHS Foundation Trust, Westminster Bridge Road, London, UK

${ }^{4}$ Department of Public Health Sciences, King's College London, London, UK ${ }^{5}$ Department of Physiotherapy, School of Health Sciences, University of Melbourne, Parkville, Melbourne, Australia

Acknowledgements The authors would like to thank the Intensive Care National Audit and Research Centre, and the Scottish Intensive Care Society Audit Group for assistance with database information for identification of organisations for participation. Furthermore the authors thank the various clinical and research network colleagues who assisted with promotion of the survey.

Contributors $\mathrm{BC}, \mathrm{LD}$ and $\mathrm{NH}$ contributed to the conception and design of the study. $B C$ and $A D$ analysed the data. $B C$ and $\mathrm{NH}$ interpreted the data. BC drafted the manuscript and all authors critically revised for significant intellectual content and insight. All authors had full access to all of the data and can take responsibility for the integrity and accuracy of data analysis. Furthermore all authors gave final approval of the manuscript version for publication. BC and NH are responsible for the overall content as guarantors.

Funding This research was supported by the National Institute for Health Research (NIHR) Biomedical Research Centre at Guy's and St Thomas' NHS Foundation Trust and King's College London. The views expressed are those of the author(s) and not necessarily those of the NHS, the NIHR or the Department of Health. Additional support was received from the Lane Fox Respiratory Unit Patients Association.

Competing interests All authors have completed the Unified Competing Interests Form at http://www.icmje.org.coi_disclosure.pdf (available from the corresponding author)

Provenance and peer review Not commissioned; externally peer reviewed.

Data sharing statement No additional data are available.

Open Access This is an Open Access article distributed in accordance with the Creative Commons Attribution Non Commercial (CC BY-NC 3.0) license, which permits others to distribute, remix, adapt, build upon this work noncommercially, and license their derivative works on different terms, provided the original work is properly cited and the use is non-commercial. See: http:// creativecommons.org/licenses/by-nc/3.0/

\section{REFERENCES}

1. Cheung A, Tansey C, Tomlinson G, et al. Two-year outcomes, health care use, and costs of survivors of acute respiratory distress syndrome. Am J Resp Crit Care Med 2006;174:538-44.

2. Herridge MS, Tansey CM, Matté A, et al. Functional disability 5 years after acute respiratory distress syndrome. $N$ Engl $J$ Med 2011;364:1293-304.

3. Hopkins RO, Weaver LK, Collingridge D, et al. Two-year cognitive, emotional, and quality-of-life outcomes in acute respiratory distress syndrome. Am J Respir Crit Care Med 2005;171:340-7.

4. Needham DM, Dinglas VD, Morris PE, et al. Physical and cognitive performance of patients with acute lung injury 1 year after initial trophic versus full enteral feeding. EDEN Trial Follow-up. $A m \mathrm{~J}$ Respir Crit Care Med 2013;188:567-76.

5. Needham DM, Davidson J, Cohen $\mathrm{H}$, et al. Improving long-term outcomes after discharge from intensive care unit: report from a stakeholders' conference. Crit Care Med 2012;40:502-9.

6. Iwashyna TJ. Survivorship will be the defining challenge of critical care in the 21st century. Ann Intern Med 2010;153:204-5.

7. Camporota L, Hart N. Lung protective ventilation. BMJ 2012;344: e2491.

8. NICE. Rehabilitation after critical illness NICE Clinical Guideline 83. London, UK: National Institute for Health and Clinical Excellence, 2009.

9. Connolly B, Denehy L, Brett S, et al. Exercise rehabilitation following hospital discharge in survivors of critical illness: an integrative review. Crit Care 2012;16:R226.

10. Griffiths J, Hatch R, Bishop J, et al. An exploration of social and economic outcome and associated health-related quality of life after critical illness in general intensive care unit survivors: a 12-month follow-up study. Crit Care 2013;17:R100.

11. NHS Right Care Atlas of Variation. http://www.rightcare.nhs.uk/ index.php/nhs-atlas/ (accessed 13 Nov 2013).

12. Jones S, Green S, Clark A, et al. Pulmonary rehabilitation following hospitalisation for acute exacerbation of COPD: referrals, uptake and adherence. Thorax 2014;69:181-2.

13. Steier J, Martin A, Harris J, et al. Predicted relative prevalence estimates for obstructive sleep apnoea and the associated healthcare provision across the UK. Thorax 2014;69:390-2.

14. Griffiths JA, Barber VS, Cuthbertson BH, et al. A national survey of intensive care follow-up clinics. Anaesthesia 2006;61:950-5.

15. Hodgin KE, Nordon-Craft A, McFann KK, et al. Physical therapy utilization in intensive care units: results from a national survey. Crit Care Med 2009;37:561-8.

16. Lewis $\mathrm{M}$. Intensive care unit rehabilitation within the United Kingdom: review. Physiotherapy 2003;89:531-8.

17. Skinner EH, Berney S, Warrillow S, et al. Rehabilitation and exercise prescription in Australian intensive care units. Physiotherapy 2008;94:220-9.

18. Appleton $\mathrm{R}$, MacKinnon M, Booth $\mathrm{M}$, et al. Rehabilitation within Scottish intensive care units: a national survey. J Intensive Care Soc 2011;12:221-7. 
19. Berry A, Cutler L, Himsworth A. National survey of rehabilitation after critical illness. J Intensive Care Soc 2013;14:334-9.

20. Department of Health. Critical care outreach 2003: progress in developing services. Department of Health and Modernisation Agency, 2003.

21. Battle C. A randomised controlled trial examining the effect of a six week supervised exercise programme on patient fitness and hospital related anxiety and depression following an intensive care length of stay of greater than 48 hours. ISCRCTN11853373 2011. http://www. controlled-trials.com/isrctn/pf/11853373

22. Griffiths R. Rehabilitating Muscle After Intensive Care (REMAIC) NCT01063738 2010. http://www.controlled-trials.gov/ct2/show/ record/NCT01063738

23. O'Neill B. Exercise after intensive care unit: a randomised controlled trial (REVIVE) NCT01463579 2011. http://www.clinicaltrials.gov/ct2/ show/NCT01463579

24. Battle $\mathrm{C}$, James K, Temblett $\mathrm{P}$, et al. Early results of a 6-week exercise programme in post-ICU patients. Crit Care 2013;17(Suppl 2):P541.

25. Medical Research Council: developing and evaluating complex interventions: new guidance. http://www.mrc.ac.uk/Utilities/ Documentrecord/index.htm?d=MRC004871 (accessed 26 Oct 2013).

26. Herridge $M$. The challenge of designing a post-critical illness rehabilitation intervention. Crit Care 2011;15:1002.

27. Connolly B, Jones G, Curtis A, et al. Clinical predictive value of manual muscle strength testing during critical illness: an observational cohort study. Crit Care 2013;17:R229.

28. Puthucheary ZA, Rawal J, McPhail M, et al. Acute skeletal muscle wasting in critical illness. JAMA 2013;310:1591-600.

29. Spruit MA, Singh SJ, Garvey C, et al. An Official American Thoracic Society/European Respiratory Society Statement: key concepts and advances in pulmonary rehabilitation. Am J Respir Crit Care Med 2013;188:e13-64.

30. Department of Health. Comprehensive critical care: a review of adult critical care services. London, 2000.

31. Prinjha S, Field K, Rowan K. What patients think about ICU follow-up services: a qualitative study. Crit Care 2009;13:R46.

32. Cuthbertson BH, Rattray J, Campbell MK, et al. The PRaCTICaL study of nurse led, intensive care follow-up programmes for improving long term outcomes from critical illness: a pragmatic randomised controlled trial. BMJ 2009;339:b3723.

33. Grimshaw J, Russell I. Effect of clinical guidelines on medical practice: a systematic review of rigorous evaluations. Lancet 1993;342:1317-22.

34. McKinlay J, Link C, Feund K, et al. Sources of variation in physician adherence with clinical guidelines: results from a factorial experiment. J Gen Intern Med 2007;22:289-306.
35. Cabana MD, Rand CS, Powe NR, et al. Why don't physicians follow clinical practice guidelines? A framework for improvement. JAMA 1999;282:1458-65.

36. Man WD-C, Polkey MI, Donaldson N, et al. Community pulmonary rehabilitation after hospitalisation for acute exacerbations of chronic obstructive pulmonary disease: randomised controlled study. BMJ 2004;329:1209.

37. NICE. Chronic obstructive pulmonary disease: management of chronic obstructive pulmonary disease in adults in primary and secondary care. NICE clinical guideline CG101. London, UK: National Institute of Clinical Excellence, 2010.

38. Seymour JM, Moore L, Jolley CJ, et al. Outpatient pulmonary rehabilitation following acute exacerbations of COPD. Thorax 2010;65:423-8.

39. TA139 Continuous positive airway pressure for the treatment of obstructive sleep apnoea/hypopnoea syndrome. National Institute of Health and Clinical Excellence. http://www.nice.org.uk/TA139 (accessed 13 Nov 2013).

40. Burkell J. The dilemma of survey nonresponse. Libr Inf Sci Res 2003;25:239-63.

41. Rubenfeld GD. Surveys: an introduction. Respir Care 2004;49:1181-5.

42. Portney L, Watkins M. Foundations of clinical research: applications to practice. 3rd edn. New Jersey, USA: Pearson Education Inc. 2009.

43. Intensive Care Society Core Standards for Intensive Care Units. Intensive Care Society. http://www.ics.ac.uk/ics-homepage/ guidelines-standards/ (accessed 13 Nov 2013).

44. Stenhammer C, Bokstrom P, Edlumd B, et al. Using different approaches to conducting postal questionnaires affected response rates and cost-efficiency. J Clin Epidemio 2011;64:1137-43.

45. Hocking J, Lim M, Read T, et al. Postal surveys of physicians gave superior response rates over telephone interviews in a randomized trial. J Clin Epidemiol 2006;59:521-4.

46. Burns K, Duffett M, Kho M, et al. A guide for the design and conduct of self-administered surveys of clinicians. Can Med Assoc J 2008;179:245-52.

47. Dillman D. Mail and internet surveys: the tailored design method. Hoboken, NJ: John Wiley \& Sons, 2007.

48. Connolly B, Thompson A, Moxham J, et al. Difficulties of patient recruitment to a post critical illness rehabilitation programme. Am J Respir Crit Care Med 2012;185: A3886.

49. Denehy L, Skinner E, Edbrooke L, et al. Exercise rehabilitation for patients with critical illness: a randomized controlled trial with 12 months of follow-up. Crit Care 2013;17:R156. 